\title{
Ocorrência de malária numa estrada recém-construída no Amazonas
}

\author{
Jack Hayes * \\ José João Ferraroni **
}

\begin{abstract}
Resumo
A maioria dos casos de malária ocorridos no Amazonas nestes últimos anos teve origem nas estradas BR-174 (Manaus/Boa Vista) e BR-319 (Manaus/Porto Velho). Este trabalho descreve o impacto da malária nos colonizadores ao longo de um trecho de $100 \mathrm{~km}$ na estrada BR-174 entre o rio Urubu e a reserva indígena Waimiri Atroari. Dados de casos de malária são apresentados assim como um inquérito foi realizado em 163 famílias residentes às margens da referida rodovia. São dadas algumas recomendações para diminuir os casos de malária nas futuras estradas a serem construídas na bacia Amazônica.
\end{abstract}

\section{INTRODUÇÃo}

Em 1974 um trecho novo da estrada BR 174 (Manaus/Boa Vista), do rio Urubu, até à reserva indígena Waimiri Atroari, ou seja, do km 99 ao 200, foi aberta para a colonização. Este setor da estrada tem sido uma área epidêmica de malária nos últimos 3 anos.

A BR 174 foi construída por estágios ou secçōes e a colonização acompanhou no mesmo sentido, desta maneira, sítios e fazendas foram surgindo com o avanço das frentes de construção. Do km 0 ao 40 , no primeiro trecho da rodovia, a colonização teve início por volta de 1965. O trecho acima do $\mathrm{km} 40$ até o 99 no rio Urubu é propriedade do governo, a qual não foi entregue à colonização. Não foi possível encontrar os dados exatos sobre a populaçãa da área estudada. O INCRA (Instituto Nacional de Colonização e Reforma Agrária) não tinha os dados naquela época. A SUCAM tem registrado uma população de 5873 em toda a extensão da BR 174. Calculamos que existem aproximadamente 3500 a 4000 habitantes, na área da estrada. Desde 1976, aproximadamente, $50 \%$ dos casos de malária ocorridos no Estado do Amazonas foram procedentes de um trecho da referida rodovia, compreendido entre os $\mathrm{km} 100$ e 200 (ver mapa em Ferraroni \& Hayes, no prelo). Nesta área, existem cepas ce Plasmodium falciparum resistentes às cloroquinas (Ferraroni et al, 1977) e amostras de Anopheles darlingi demostram um comportamento de resistência ao DDT (Hayes \& Charlwood, 1977). Esses fatores foram responsáveis pelo início de um estudo sobre dinâmica populacional (distribuição sazonal) do Anopheles darlingi (Hayes \& Charlwood, 1978).

Num esforço para determinar o impacto que a malária causa nos colonizadores, um inquérito foi realizado em março de 1978, numa secção da estrada BR 174 entre os km 99 e 200. A área acima do $\mathrm{km} 200$ até à reserva Indígena é área militar, a qual não foi incluída no trabalho.

A ocorrência de infecção malárica no pessoal militar não foi totalmente avaliada, sendo computados somente os dados dos pacientes hospitalizados (Ferraroni \& Hayes, no prelo). A BR 174 (Manaus/Boa Vista) foi aberta completamente para o tráfico em março de 1976.

\section{MATERIAIS E MÉTODOS}

A equipe que realizou o inquérito foi constituída por dois assistentes de campo, os quais foram treinados para aplicar os questionários nos colonizadores. Eles usaram motocicletas, como meio de transporte, para visitar as residências dos moradores nas margens da estrada. O questionário foi aplicado sempre ao chefe da familia (marido ou mulher). Eram gastos um tempo médio de 15 minutos na entrevista da aplicação do questionário, o qual envolvia perguntas formuladas aos colonizadores e observações do próprio entrevistador. Os questionários realizados durante o dia eram conferıdos a noite por um de nós (J. H.) para

(*) - Instituto Nacional de Pesquisas da Amazônia, Manaus

(*) - Instituto Nacional de Pesquisas da Amazônia e Hospital de Moléstias Tropicais de Manaus - Amazonas. 
assegurar uma completa uniformidade na coleta dos dados. As operações foram baseadas nos estudos feitos em laboratório de campo existente no $\mathrm{km} 137$. Todos os números de km escritos neste trabalho são baseados na nova quilometragem, o que representa $16 \mathrm{~km}$ a menos que a numeração antiga.

\section{INFORMAÇÕES SOLICITADAS E OBSERVAÇÕES}

I(') - Neste item foi observado o $\mathrm{km}$ de localização e o tipo de casa, esta baseada na facilidade para o acesso de mosquitos, com a seguînte classificação :

O - Casas construídas de madeiras e foThas de palmeiras com ausência de uma ou duas paredes externas;

1 - Casas com quatro paredes externas mas com portas e janelas abertas permanentemente;

2 - Casas com 4 paredes externas sólidas, bem construídas, mas com espaços grandes, abertos para ventilação, geralmente entre o telhado e as paredes:

3 - Casas com 4 paredes externas, bem construídas com telas nas janelas, mas com espaços abertos onde os mosquitos poderiam ter acesso;

4 - Casas a prova de mosquitos, com paredes externas bem construidas e telas nas janelas.

II (') - Número de redes ou camas com mosquiteiros, a classificação foi a seguinte:

0 - Ausência completa de mosquiteiros na casa;

1 - Algumas camas ou redes com mosquiteiros;

2 - Todas as camas ou redes com mosquiteiros.

III - Nome do proprietário, caso não fosse o proprietário, era anotado o nome do morador, chefe da família e do entrevistado.

IV - Escolaridade do chefe da familia; esta parte era só escrita no momento e posteriormente classificado em :

$$
\begin{aligned}
& 0 \text { - Analfabeto; } \\
& 1 \text { - Alfabetizado (fundamental); }
\end{aligned}
$$

2 - Primário completo;

3 - Colegial completo;

4 - Universitário.

$\mathrm{V}$ - Idade e sexo de cada membro da família visitada.

VI - O ano de chegada à localidade. Até essa questão o entrevistador foi instruido a não mencionar a palavra malária, para não infiuenciar as perguntas VII e VIII.

VII - Perguntava-se aos colonizadores Como vocês adquirem malária? As respostas foram catalogadas em :

$$
\begin{aligned}
& 0 \text { - Não sabe; } \\
& 1 \text { - Água suja; } \\
& 2 \text { - Mosquitos; } \\
& 3 \text { - Outros. }
\end{aligned}
$$

VIII - Nesta questão perguntava-se: Como você sabe quando está acometido de malária? As respostas foram classificadas em :

0 - Não sabe;

1 - Febre e frio;

2 - Vômito e diarréia;

3 - Febre, frio e cefaléia;

4 - Outros.

IX - O número de vezes que cada pessoa teve malária nos últimos seis meses, foi anotado por sexo, idade e espécie do plasmódio, anotou-se também o número de dias de trabalhos perdidos devido à infecção malárica.

$X$ - Perguntou-se aos colonizadores o que eles fazem quando contraem malária. As respostas foram classificadas como se segue:

0 - Espera pela SUCAM, para exame e tratamento;

1 - Vão para a SUCAM no km 200;

2 - Vão para o Hospital de Moléstias Tropicais em Manaus;

3 - Vão para a SUCAM em Manaus;

4 - Tratamento por seus próprios meios;

5 - Outros;

6 - Ainda não tiveram malária.

$\mathrm{XI}$ - Foi perguntando se a SUCAM lhes trazia algum benefício, as respostas foram catalogadas em sim e não.

XII - Perguntou-se aos colonizadores se eles tinham medicamentos em casa para

(1) - Dados obtidos por observação. 
tratar malárla. Caso a resposta fosse positiva eles mostravam a droga sendo classificadas em :

0 - Cloroquina distribuída pela SUCAM;

1 - Medicamentos adquiridos em farmácias;

2 - Outros.

Perguntou-se ainda se eles tinham alguma sugestão a dar para resolver o problema da malária.

Todas as respostas foram ugrupadas por setores :

$$
\begin{array}{clcr}
\text { Setor } & \text { I } & \text { Km } & 99-124 ; \\
" & \text { II } & " & 125-139 ; \\
" & \text { III } & \text { " } & 140-155 ; \\
" & \text { IV } & \text { " } & 156-170 ; \\
\text { " } & \text { V } & \text { " } & 171-200 ;
\end{array}
$$

Os dados da SUCAM foram obtidos no escritório central daquele órgão do Ministério da Saúde em Manaus. Alguns dados de campo foram conseguido nas visitas feitas à estrada, pelo laboratório móvel (ônibus) do FUNRURAL $\left({ }^{2}\right)$ e Hospital de Moléstias Tropicais de Manaus (fins de semana). Este ônibus faz atendimento à população da estrada BR 174 , uma vez por mês nos $\mathrm{km} 124,133,150$ e 178 , onde os casos febris são examinados hematoscopicamente para malária.

\section{RESUltados E DISCUSSÃo}

Cento e sessenta e três chefes de famílias colonizadoras foram entrevistados, $39 \%$ não eram proprietários dos terrenos, $40 \%$ não sabiam ler nem escrever e $50 \%$ tinham apenas terminados os dois primeiros anos do primário, ou seja, instrução fundamental, os quais poderiam ser considerados alfabetizados (ta-

\begin{tabular}{|c|c|c|c|c|c|c|c|}
\hline Especificą̧ăo & 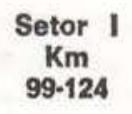 & $\begin{array}{c}\text { Setor II } \\
\text { Km } \\
125-139\end{array}$ & $\begin{array}{c}\text { Setor III } \\
\text { Km } \\
140-155\end{array}$ & $\begin{array}{c}\text { Setor IV } \\
\mathrm{Km} \\
156-170\end{array}$ & 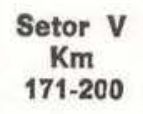 & Total & $\%$ \\
\hline $\begin{array}{l}\text { Proprietário do terreno } \\
\text { Moradores năo proprietários }\end{array}$ & 28 & 23 & 18 & 8 & 22 & 99 & 61 \\
\hline do terreno & 11 & 9 & 18 & 11 & 15 & 64 & 39 \\
\hline Total de casas & 39 & 32 & 36 & 19 & 37 & 163 & 100 \\
\hline \multicolumn{8}{|l|}{ Nivel educacional } \\
\hline Analfabetos & 13 & 17 & 23 & 6 & 7 & 66 & 40 \\
\hline Alfabetizados & 24 & 15 & 11 & 10 & 21 & 81 & 50 \\
\hline Primário completo & 2 & 0 & 2 & 2 & 9 & 15 & 9 \\
\hline Colegial & 0 & 0 & 0 & 1 & 0 & 1 & 1 \\
\hline Universidade & 0 & 0 & 0 & 0 & 0 & 0 & 0 \\
\hline Total & 39 & 32 & 36 & 19 & 37 & 163 & 100 \\
\hline \multicolumn{8}{|l|}{ Ano de chegada } \\
\hline 1978 & 8 & 2 & 1 & 1 & 4 & 16 & 10 \\
\hline 1977 & 18 & 14 & 10 & 7 & 19 & 68 & 42 \\
\hline 1976 & 5 & 8 & 8 & 2 & 7 & 30 & 18 \\
\hline 1975 & 7 & 1 & 9 & 4 & 5 & 26 & 16 \\
\hline 1974 ou antes & 1 & 7 & 8 & 5 & 2 & 23 & 14 \\
\hline Total & 39 & 32 & 36 & 19 & 37 & 163 & 100 \\
\hline
\end{tabular}
bela 1). Apenas $15(9 \%)$ dos chefes de familias cursaram o primário completo. Somente

TABELA 1 - Famílias residentes na BR-174 (Manaus/Boa Vista) : relacionando as residências, nível de culturas, anos de chegada, proprietários e moradores

(2) - Fundo Nacional de Assistência ao Trabalhador Rural. 
um entrevistado tinha cursado o ginásio. Nenhum tinha curso universitário. A maioria dos colonizadores é oriunda do Estado do Amazonas: $50 \%$ vieram de Manaus e $17 \%$ de áreas vizinhas a Manaus, ou seja do Estado do Amazonas: $16 \%$ deles vieram de alguma localidade da Bacia Amazônica, geralmente de Estados vizinhos ao Amazonas e 20 indivíduos (12\%) foram procedentes de outras localidades fora da Amazônia, dos sêguintes Estados: Ceará (11), Maranhão (6), Espirito Sâıto (1), Goiás (1) e Minas Gerais (1), (Ver também tabela 2).

Assim que os colonizadores chegavam à área, construiam casas apenas para se protegerem da chuva e do sol (barraca), algumas vezes sem paredes. Posteriormente, faziam outras melhorias, construindo outros cômodos e fazendo as paredes laterais e, às vezes até assoalho. É comum encontrarem-se casas apenas com duas paredes laterais e áreas acima das paredes, abertas para entrada de ventilação; freqüentemente esse espaço contém mais de um metro: Geralmente, no segundo ano de chegada à área, o colonizador pode comprar algumas madeiras trabalhadas (tábuas) da serraria existente no $\mathrm{km} 198 \mathrm{e}$, constantemente, fazem um assoalho elevado do solo e paredes mais compactas. As casas foram classicadas, de acordo com a facilidade de entrada dos mosquitos: $39 \%$ delas apresentavam-se com ausência de uma ou duas paredes externas (tipo 0 ); $27 \%$ tinham janelas e portas abertas permanentementes (tipo 1) (tabela 2), trinta e três por cento poderiam ser consideradas bem construídas, mas com alguns espaços grandes para ventilação, principalmente entre o telhado e as paredes (tipo 2) . Somente 3 casas das 163 poderiam ser consideradas quase protegidas de mosquitos (tipo 3). Não houve nenhuma casa que estivesse completamente à prova de mosquitos, com janelas protegidas por tela e paredes externas bem construídas (tipo 4). Das casas visitadas, $71 \%$ não tinham mosquiteiros, $17 \%$ tinham alguns mosquiteiros, mas não em todas

TABELA 2 - Familias residentes na BR-174 (Manaus/Boa Vista) relacionando: Moradores por setor, localidade de origem e a utilização de mosquiteiros pelos moradores

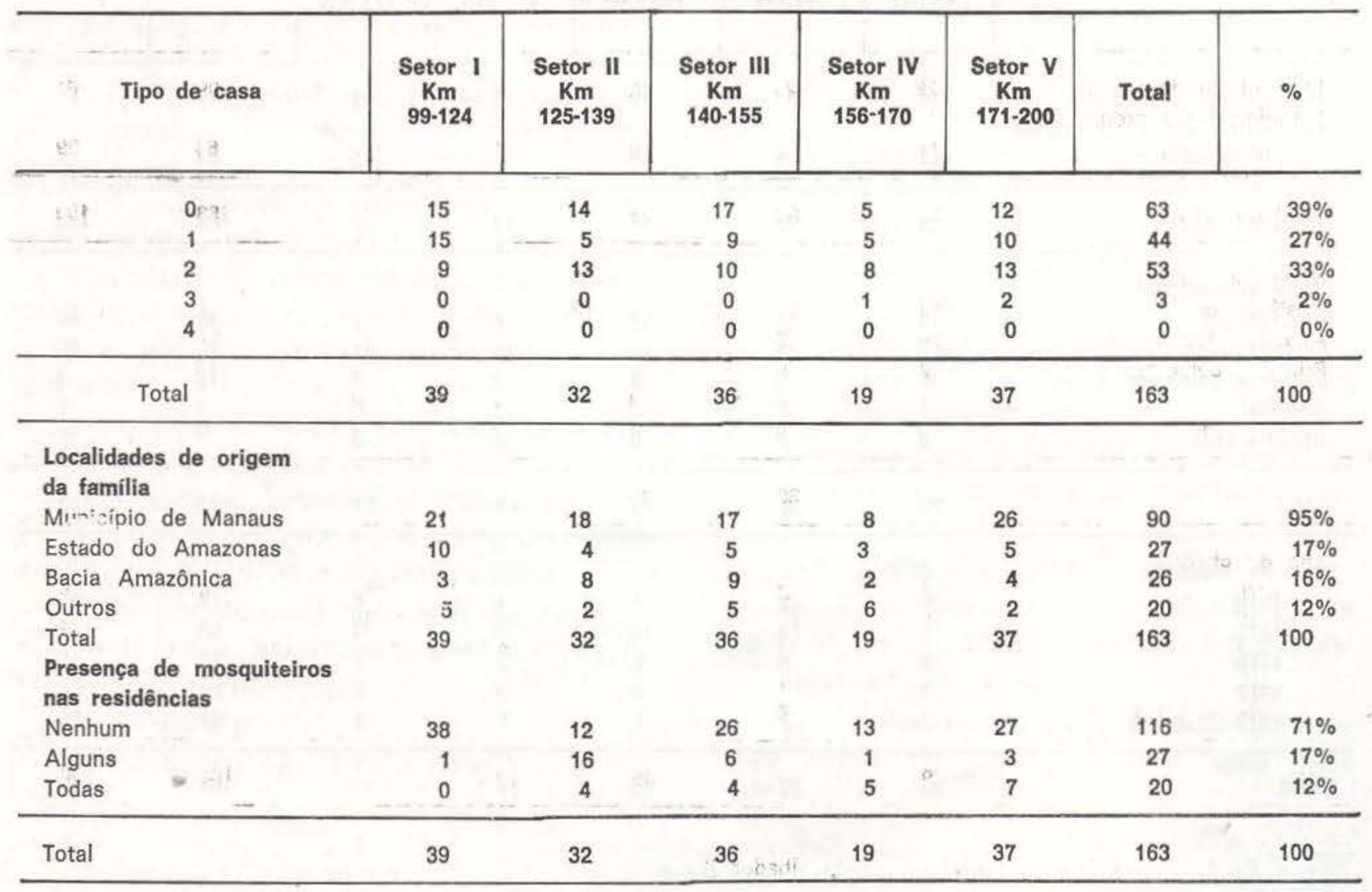


TABELA 3 - Famílias residentes na BR-174 (Manaus/Boa Vista) relacionando: respostas ao questionário sobre sintomas e transmissão da malária

\begin{tabular}{|c|c|c|c|c|c|c|c|}
\hline Especificaçăo & $\begin{array}{c}\text { Setor I } \\
\mathrm{Km} \\
99-124\end{array}$ & 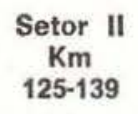 & $\begin{array}{l}\text { Setor III } \\
\text { Km } \\
140-155\end{array}$ & $\begin{array}{c}\text { Setor IV } \\
\mathrm{Km} \\
156-170\end{array}$ & $\underset{171-200}{\substack{\text { Setor } \\
\text { Km }}}$ & Total & $\%$ \\
\hline \multicolumn{8}{|l|}{$\begin{array}{l}\text { Conhecimentos sobre a } \\
\text { transmissão da malária }\end{array}$} \\
\hline Não sabe & 13 & 8 & 4 & 2 & 2 & 29 & $17 \%$ \\
\hline Água suja & 11 & 5 & 15 & 6 & 9 & 46 & $28 \%$ \\
\hline Mosquitos & 13 & 16 & 15 & 9 & 19 & 73 & $45 \%$ \\
\hline Outros & 2 & 3 & 1 & 2 & 7 & 17 & $10 \%$ \\
\hline Total & 39 & 32 & 36 & 19 & 37 & 163 & $100 \%$ \\
\hline \multicolumn{8}{|l|}{$\begin{array}{l}\text { Conhecimentos sobre os } \\
\text { sintomas da malária }\end{array}$} \\
\hline Não sabe & 8 & 2 & 4 & 0 & 0 & 14 & $9 \%$ \\
\hline Febre frio & 12 & 21 & 6 & 6 & 8 & 53 & $33 \%$ \\
\hline Diarréia e vômitos & 0 & 0 & 1 & 0 & 2 & 3 & $2 \%$ \\
\hline Febre frio-cefaleia & 18 & 9 & 24 & 13 & 22 & 86 & $52 \%$ \\
\hline Outros & 1 & 0 & 1 & 0 & 5 & 7 & $4 \%$ \\
\hline Total & 39 & 32 & 36 & 19 & 37 & 163 & $100 \%$ \\
\hline
\end{tabular}

as redes e camas e somente $12 \%$ das casas pesquisadas tinham mosquiteiros em todas as redes e camas (tabela 2 ). O preço de um mosquiteiro era em torno de 200 a 250 cruzeiros no momento da pesquisa. Os colonizadores mostraram ter bons conhecimentos sobre os sintomas, pois $85 \%$ responderam ter febre e frio com ou sem cefaléia (tabela 3 ). Somente $9 \%$ responderam não ter idéia da sintomatologia. Com relação a pergunta de número sete, poderíamos pensar em ter havido certa influência, uma vez que as visitas foram feitas através de mutocicletas e o técnico da SUCAM, quando percorre as residências para a pesquisa de plasmódio, nos casos febris, também usa motocicleta. Quarenta e cinco por cento das pessoas entrevistadas responderam que o mosquito era o responsável pela transmissão, $17 \%$ responderam não saber como a malária é transmitida, $28 \%$ asseguraram que a transmissão se processa através da água suja e 10\% disseram outras coisas, tais como: sujeira no ar. patos na água, mau cheiro, etc.. Smith (1976)), numa situação similar, na rodovia transamazônica, obteve $43 \%$ de respostas incriminando mosquitos como o transmissor.
MALÁRIA E O COLONIZADOR - De acordo com o Diretor do Hospital Geral de Manaus, quase todos os casos de malária no pessoal militar estavam associados à BR 174 . O $6^{\circ} .^{\circ}$ BEC (Batalhão de Engenharia e Construção) foi responsável pela construção e atualmente está sendo incumbido da manutenção da estrada. Existem vários acampamentos sediados na rodovia para assegurar a sua boa manutençăo; dois deles no km 100 onde foi realizado este inquérito. Baseado neste fato, é obvio que a malária existe na área desde o início da construção da estrada.

No Hospital de Moléstias Tropicais de Manaus existem 1633 casos de malária diagnosticados e 802 hospitalizados nos anos de 1976 e 1977; praticamente $50 \%$ dos casos atendidos foram hospitalizados (Ferraroni \& Hayes, 1978). Não devemos fazer o mesmo raciocínio, com relação aos pacientes militares dado o critério usado para a hospitalizaçăo ser um pouco diferente, assim como a exposiçăo do indivíduo à transmissão (tabela 6 ). Somente os dados dos militares foram incluídos entre todo o pessoal atendido e tratado no $\mathrm{km} 200$. Não foi possível obter dados do pessoal civil 
que trabalhava com os militares uma vez que este tipo de população é bastante instável na área.

A ocorrência de malária nos colonizadores está representada nos gráficos 1 e 2 neles podemos verificar que praticamente o mesmo grupo etário com malária é aproximadamente a metade do total nos últimos 6 meses.

A incidência mais elevada de malária ocorre no final da estação seca quando a população de Anopheles darlingi é mais alta; :sto ocorreu no final de setembro de 1977 (Hayes \& Charl- wood, no prelo). O número de mosquito decresce com o prolongar da estação chuvosa e os casos de malária acompanham a mesma curva porém, num período mais atrasado.

Habitações com casos de infecção malárica aumentam em freqüência de $51 \%$ no setor I para $97 \%$ na área ao redor do $\mathrm{km} 170$ (tabela 5). As residências com indivíduos apresentando mais de uma infecção também aumentam de sul para norte: $26 \%$ no setor I para o máximo de $68 \%$ ro setor III. Existem várias explicações possiveis, mas nenhuma prova. Os

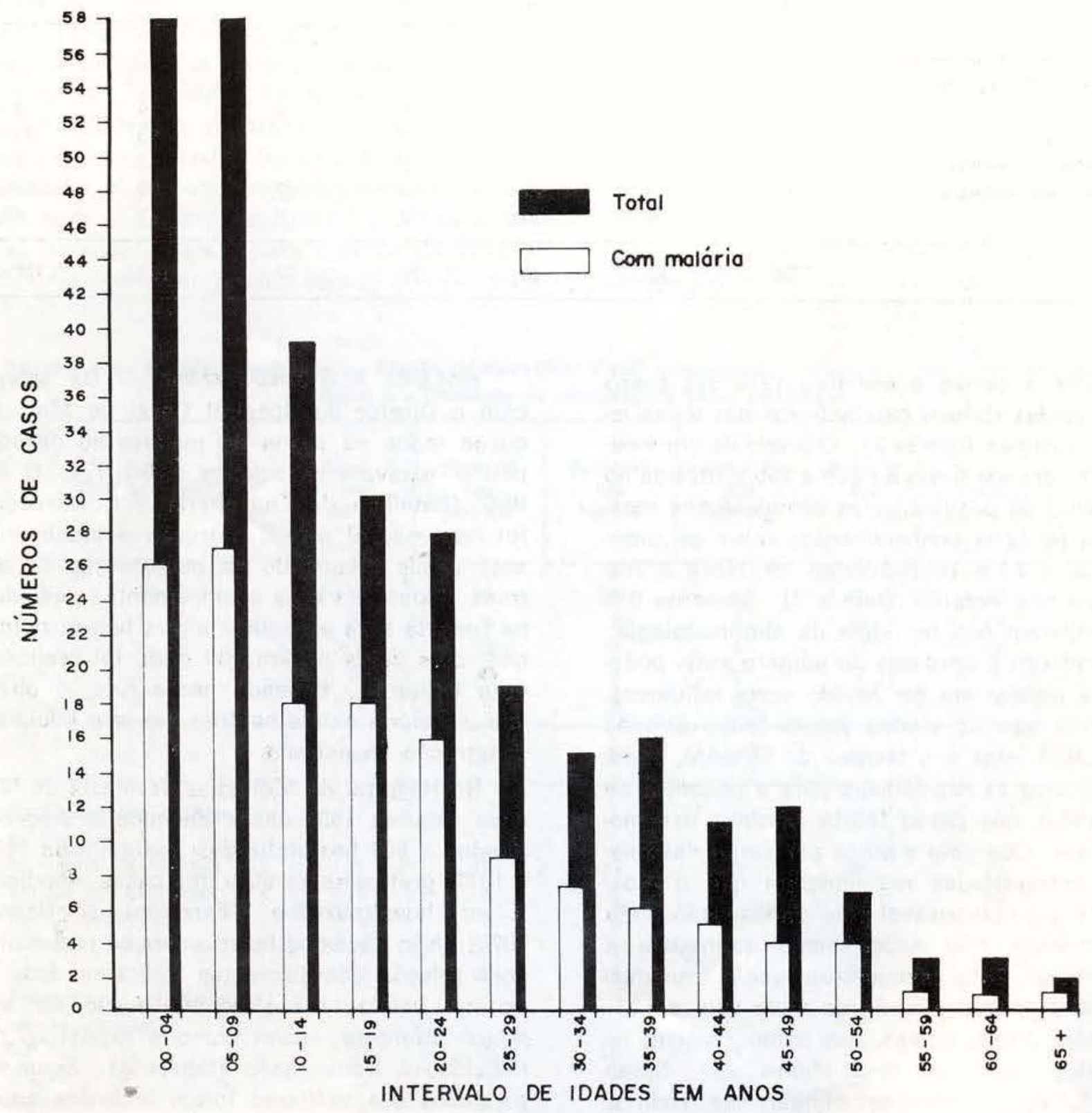

GRÁFICO 1 - Malária na população feminina da BR-174 (Km 99-200), no período de setembro de 77 a fevereiro de 78 


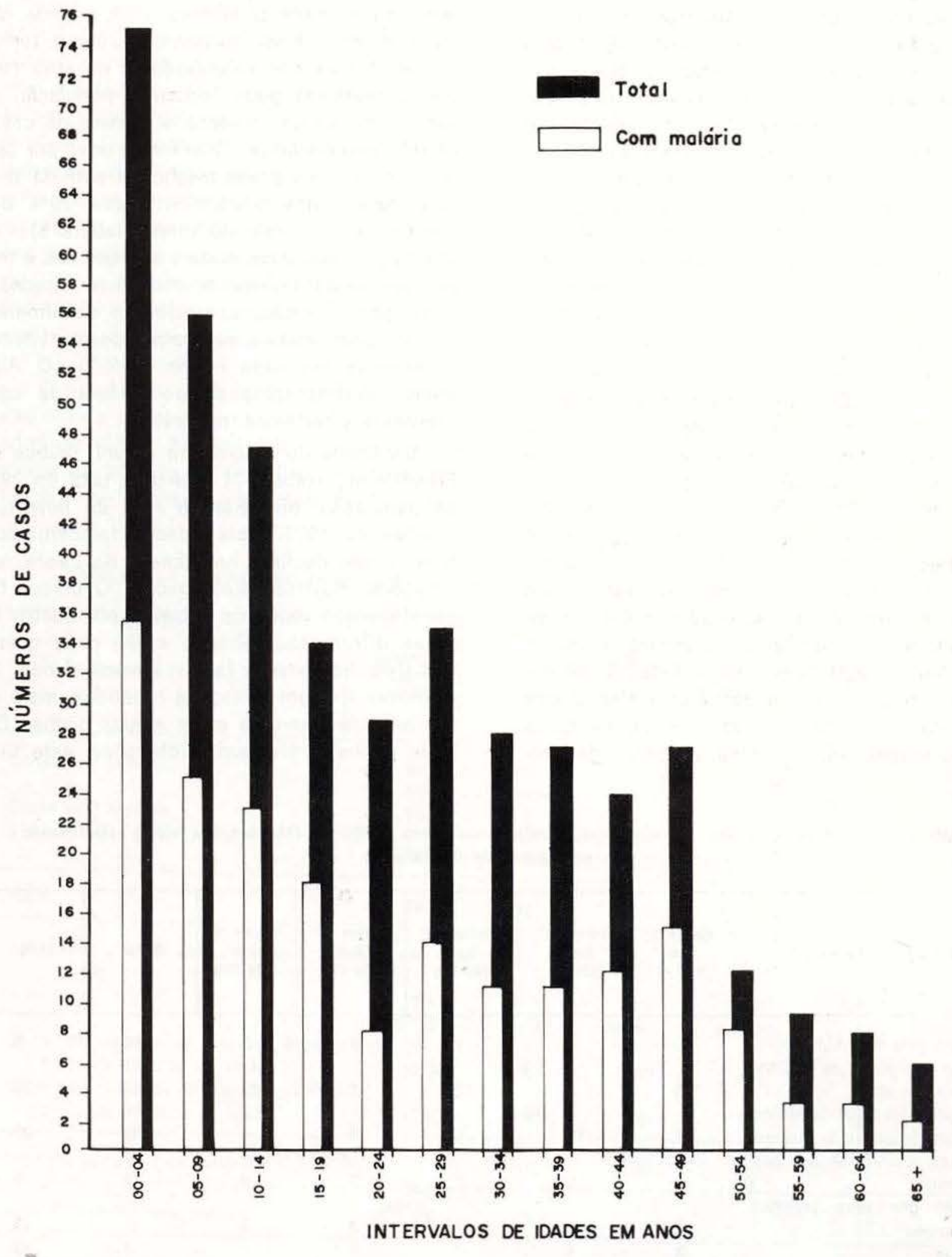

GRAFICO 2 - Malária na população masculina da BR-174 (Km 99-200), no período de setembro de 77 a fevereiro de 78 
dados não existem no Instituto Nacional de Colonização e Reforma Agrária (INCRA), que controla os direitos dos colonizadores sobre a exploração das terras desde sua chegada à área. Os mapas de borrifação da SUCAM e nossas observações demostram que deve ter existido algumas casas, nesse trecho de 100 $\mathrm{km}$ da estrada desde 1974. Entretanto a quantidade de desmatamento nas margens desta rodovia diminui quando se viaja, no sentido norte com exceção das proximidades do $\mathrm{km}$ 190 onde existem diversas fazendas com grandes áreas desmatadas, dado existir nas proximidades uma grande companhia (Serragro) de beneficiamento de madeira bruta.

Existem poucas famílias nos últimos 10 $\mathrm{km}$ (190-200). O desmatamento deve afetar de alguma maneira a população do vetor; é possível que a distância da floresta às residências $\mathrm{e}$ até aos locais dos criadouros seja crítica para - Anopheles darlingi. Todos os anos, os colonizadores avançam o desmatamento, isto é facilmente verificado quando se viaja pela estrada: cada vez mais à frente existem menos espaços limpos. As localidades próximas de Manaus foram selecionadas primeiro, dadas as facilidades oferecidas pela cidade. Também, quando as árvores são derrubadas das lagoas formadas pelos aterros da rodovia, as quais tem drenagem insuficientes, os sítios de ovo- posição ficam expostos à luz solar. A sombra parece ser um fator crítico para o sucesso da larva do A. darlingi (Hayes, dados ainda não publicados). Desta maneira, o curto tempo das atividades dos colonizadores na área (trocas ecológicas) pode reduzir a população do vetor e conseqüentemente o número de casos de infecção malárica. Quarenta e nove por cento da população deste trecho da estrada tiveram malária nos últimos 6 meses, $39 \%$ dos homens e $48 \%$ das mulheres (tabela 5). As diferenças nas taxas podem ser devidas a menor exposição do homem, como nas caçadas à noite pela floresta, as mulheres usualmente, não viajavam após o escurecer, permanecendo geralmente em casa nesse período. O Anopheles darlingi pica dentro e fora da casa (Hayes \& Charlwood, no prelo).

Os dados do laboratório móvel, ônibus do FUNRURAL, (tabela 7) dão uma taxa de $29 \%$ da população infectada do mês de janeiro a outubro de 1977. Estes dados também mostram algum declínio no número de casos nas estações chuvosas prolongadas. O ônibus faz atendimentos todos os sábados em quatro lugares diferentes, voltando então cada quatro semanas no mesmo local. Destes dados, 23 mulheres tiveram infecções repetidas, mais de um mês de intervalo entre alguns casos. Catorze mulheres tiveram 2 infecções, sete tive-

TABELA 4 - Preferência dos colonizadores, famílias residentes na BR-174 (Manaus/Boa Vista) relacionando: o acontecimento de malária

\begin{tabular}{|c|c|c|c|c|c|c|c|}
\hline Especific ação & $\begin{array}{c}\text { Setor I } \\
\mathrm{Km} \\
99-124\end{array}$ & $\begin{array}{c}\text { Setor II } \\
\text { Km } \\
125-139\end{array}$ & $\begin{array}{c}\text { Setor III } \\
\text { Km } \\
140-155\end{array}$ & $\underset{156-170}{\substack{\text { Setor IV } \\
15 m}}$ & $\underset{171-200}{\substack{\text { Setor } \\
\text { Km }}}$ & Total & $\%$ \\
\hline $\begin{array}{l}\text { Espera pela SUCAM } \\
\text { Procura ao posto da SUCAM }\end{array}$ & 1 & 6 & 1 & 3 & 2 & 13 & 8 \\
\hline $\begin{array}{l}\text { - Km } 200 \\
\text { Procura o Hospital de Molés- }\end{array}$ & 5 & 5 & 12 & 5 & 27 & 54 & 33 \\
\hline tias Tropicais de Manaus & 5 & 11 & 6 & 5 & 4 & 32 & 20 \\
\hline $\begin{array}{l}\text { Procura a SUCAM em Ma- } \\
\text { naus }\end{array}$ & c & 1 & 2 & 2 & 0 & 5 & 3 \\
\hline $\begin{array}{c}\text { Tratam por seus próprios } \\
\text { meios }\end{array}$ & & 5 & 5 & 3 & 3 & 21 & 13 \\
\hline $\begin{array}{l}\text { meios } \\
\text { Outros }\end{array}$ & $\begin{array}{l}5 \\
3\end{array}$ & $\begin{array}{l}5 \\
1\end{array}$ & 1 & 0 & 0 & 5 & 3 \\
\hline Ainda não adquíriram malária & 19 & 3 & 9 & 1 & 1 & 33 & 20 \\
\hline TOTAL & 39 & 32 & 36 & 19 & 37 & 163 & 100 \\
\hline
\end{tabular}


ram 3 infecçōes e duas tiveram 4 infecçöes. Para os homens, os dados são similares: 29 homens tiveram infecções múltiplas: dezenove com 2 infecções, quatro com 3 infecções, dois com 4 infecções, três com 5 infecções e um com 7 infecções. As taxas de infectibilidades foram praticamente iguais para $P$. falciparum e $P$. vivax. Freqüentemente, o ônibus só distribui derivados de sulfas para $\alpha$ tratamento da malária falciparum; desta maneira, recrudescência devem ser consideradas em adição aos casos de novas transmissőes (tabela 5). Menos de $1 \%$ da população que participou do inquérito prefere a equipe do ônibus para o tratamento da malária (tabela 4).

O número de dias de trabalhos perdidos é alto para a populaçăo masculina de mais de 10 anos de idade; 128 indivíduos perderam uma média de 38 dias de trabalho por caso de infecção. As mulheres com mais de 10 anos de idade perderam uma média de 42 dias (tabela 5). Isto confere com o aumento de dias de internamento para mulheres quando comparados com homens (Ferraroni \& Hayes, no prelo). Um dos fatores mais importantes na transmissăo deve ser o movimento apresentado pela população: $10 \%$ do pessoal que participou do inquérito chegaram à área nos últimos 60 dias e $42 \%$ no último ano (1977), dezoito por cento chegaram em 1976, 16\% em 1975 e $14 \%$ em 1974 ou antes (tabela 1). Isto indica uma grande mudança e, muito provavelmente, um mecanismo complicado de malária naqueles prováveis suceptíveis, recém-chegados à área, onde a infecção é responsável pelo maior número de vítimas. Nos últimos 16 meses um de nós (J. H.) trabalhou neste trecho da estrada e observou que na área próximo ao laboratório de campo ( $\mathrm{km} \mathrm{137)}$ algumas familias deixaram o local dados os freqüentes casos de infecçăo malárica.

TABELA 5 - Familias residentes na BR-174 (Manaus/Boa Vista) relacionando: Incidência da malária

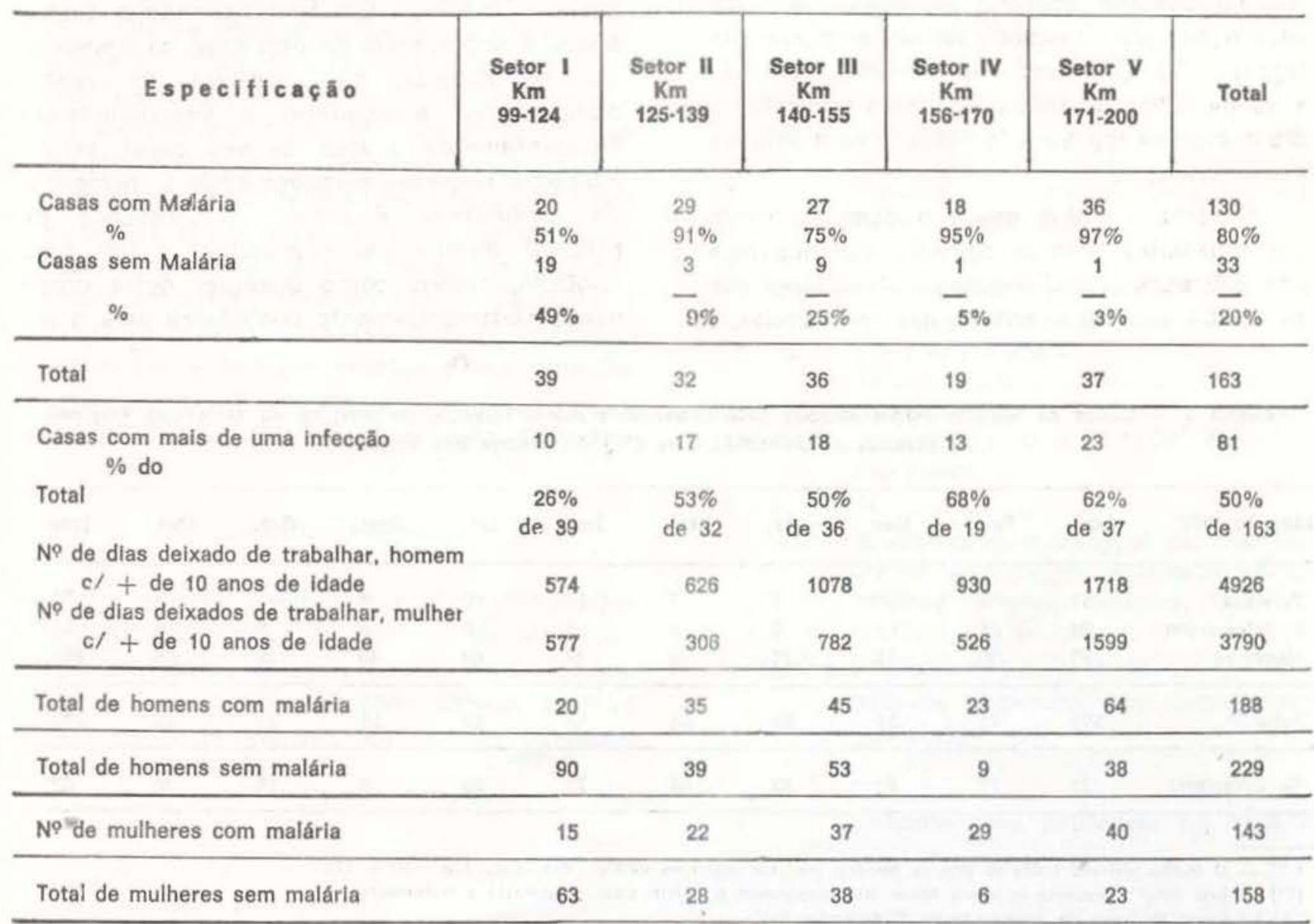


TABELA 6 - Casos de malária tratados no Hospltal Geral de Manaus (Hospital Militar) durante quatro anos, de 1974 a 1977.

\begin{tabular}{r|r|r|r|r|r|r}
\hline Ano & P. vivax & $\%$ & P. falciparum & $\%$ & Total & $\%$ \\
\hline 1974 & 8 & 18 & 7 & 11 & 15 & 14 \\
1975 & 18 & 41 & 19 & 31 & 37 & 35 \\
1976 & 14 & 32 & 22 & 35 & 36 & 34 \\
1977 & 4 & 9 & 14 & 23 & 18 & 17 \\
\hline Total & 44 & 100 & 62 & 100 & 106 & 100 \\
\hline
\end{tabular}

\section{CONCLUSÕES}

Muitos fatores parecem contribuir para a ocorrência de malária nesta área. Para o futuro desenvolvimento da bacia Amazônica, são sugeridas algumas recomendações: As construções das estradas deverão ser feitas com drenagem adequada dos aterros, fazendo o possível para não deixarem águas estagnadas, em formas de pequenas lagoas. Quando isto não for possível, cortar as árvores que ficam dentro da água, evitando deixar sombras nas lagoas. Os colonizadores deverão construir suas moradias próximas às fontes correntes $\mathrm{e}$ distantes das represas formadas pelos ambientes naturais.

Maiores estudos sobre o comportamento dos mosquitos vetores deverão ser incentivados e financiados. O mosquito $A$. darlingi evita o DDT que foi borrifado nas residências e repousa nas vegetações das proximidades. Se removermos esta vegetação das vizinhanças das casas, e construirmos casas de paredes externas bem protegidas, ou mesmo usando telas, poderíamos afirmar que um menor número de transmissão iria ocorrer. Medidas antimosquitos, pelo menos até o presente momento, parecem ser muito discutidas a despeito da detetização das casas cada 6 meses, pois as taxas de malária nesta área continua indicando uma alta endemicidade. Algumas alternativas para o DDT deverão ser exploradas. Atualmente, estão sendo realizados estudos com aplicação de baixo volume residual de malathion; um programa bem coordenado deverá comprovar sua eficiência, contudo deverão ser feitos testes para avaliar a suscetibilidade nas linhas básicas para determinar resistência. Um controle integrado seria o ideal, mas não é praticável, no momento, pois poucas pesquisas estão sendo efetuadas acerca dos fatores ecológicos acima mencionados.

A falta de educação e o nível sócio-econômico baixo são fatores que predispõem o caboclo à malária. Ele freqüentemente desconhece a importância do mosquito na transmissão da malária, não podendo, às vezes, comprar um mosquiteiro e desconhecendo freqüentemente $\sigma$ valor de seu papel, principalmente naquelas estações onde a incidência de Anofelinos é maior. A presença da SUCAM distribuindo cloroquina, é um bom controle, porém, como qualquer outra droga usada sistematicamente contribuirá para o au-

TABELA 7 - Casos de malária diagnosticados pela Laboratório móvel (ônibus) do Hospital de Moléstias Tropicais de Manaus e FUNRURAL', na BR-174 (Manaus/Boa Vista)

\begin{tabular}{|c|c|c|c|c|c|c|c|c|c|c|c|}
\hline Mês de 1977 & Jan. & Fev. & Mar. & Abr. & Mai. & Jun. & Jul. & Ago. & Set. & Out. & Total \\
\hline P. vivaz & 11 & 5 & 8 & 6 & 7 & 11 & 12 & 8 & - & 8 & 76 \\
\hline P. falciparum & 25 & 6 & 11 & 9 & 8 & 13 & 6 & 6 & 2 & 8 & 94 \\
\hline Negativo & 73 & 30 & 12 & 21 & 29 & 44 & 64 & 40 & 29 & 65 & 408 \\
\hline Total $\cdots$ & 109 & 41 & 31 & 36 & 44 & 68 & 82 & 54 & 31 & 82 & 578 \\
\hline$\%$ c/malária & 33 & 27 & 61 & 42 & .34 & 22 & 26 & 6 & 16 & 29 & 29 \\
\hline
\end{tabular}

(*) - o ônibus visitova todos os fins de semana um dos seguintes locois: $\mathrm{Km} .124,133,150$ e 178.

(*) - Esse total representa os casos febris que procuraram o ônibus para diagnóstico e tratamento.

(1) - Fundo Nacional de Assistência ao Trabalhador Rural. 
mento de resistência à malária. De 40 famílias tenda medicamentos contra malária em suas residências, 24 tinham cloroquina distribuída pela SUCAM. Para o paciente, a dose curativa é de 4 comprimidos, no primeiro dia e 3 por dia nos dois dias seguintes. Freqüentemente, o paciente sente-se melhor no segundo dia e interrompe o tratamento, guardando o medicamento para uma próxima oportunidade, ou para seus filhos, ou ainda para pessoas de sua família e vizinhos que apresentar febre. Somente $8 \%$ das pessoas esperam pela SUCAM (tabela 4) para o tratamento. Mais da metade dos indivíduos entrevistados procuraram tratamento em Manaus ou no posto militar no km 200. Isto significa perda de tempo e dinheiro para o caboclo que gasta uma média de 80 a 100 cruzeiros para ir até Manaus, dependendo, é claro, do setor onde ele se encontra. Se eles

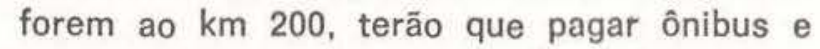
esperar o dia seguinte para voltar. Outro fator importante é que $13 \%$ dos colonizadores tratam malária por seus próprios meios. $\mathrm{Na}$ época do inquérito, a primaquina era encontrada só no escritório central da SUCAM em Manaus, não se podendo adquirí-la em farmácias. Parece ser imperativo que um tratamento completo deve ser feito ou os meios de transportes deverăo ser facilitados, nas áreas endêmicas de modo que os pacientes possam atingir o principal posto de coordenação, onde todas as drogas são viáveis. A última resposta para malária seria uma vacina humana, mas isto não é para um futuro imediato (Speer, Ferraroni \& Hayes, no prelo). Até esse tempo, a malária continuará a ser um problema nas estradas recém-construídas na Bacia Amazônica, a não ser que medidas preventivas sejam tomadas.

\section{AGRADECIMENTOS}

Os autores agradecem ao $\mathrm{Dr}$. Heitor Vieira Dourado, Diretor do Hospital de Moléstias Tropicais de Manaus por facilitar alguns dados; ao Dr. Antonio Maia Barbosa, Diretor do Hospital Geral de Manaus por colocar os dados do SAME à nossa disposição; ao Dr. Joel Afonso, chefe da equipe médica de campo do Hospital de Moléstias Tropicais por facilitar nosso acesso até os colonizadores em algumas viagens e por ceder-nos alguns dados dos exames hematoscópicos e à equipe da SUCAM pela colaboração prestada na realização da pesquisa.

\section{SUMMARY}

The majority of malaria cases in Amazônia for the past few years has been on the newly opened roads: BR-174 (Manaus/Boa Vista) e BR-319 (Manaus/Porto Velho). This research describies the impact of malaria on the colonist along a $100 \mathrm{~km}$ section of BR-174 North of rio Urubu. Malaria statistics for this area are presented and the results of a survey of 163 residences. Recommendations given to lower the potential threat of malaria for the colonists on future roads in Amazon basin.

\section{BIBLIOGRAFIA CITADA}

FERrARoni, J.J. \& HAYES, J.

- Aspectos epidemiológicos da malária no Amazonas. Acta Amazonica (no prelo).

FERRARONI, J.J.; WAKI, S. \& SUZUKI, M.

1977 - Resistência do Plasmodium falciparum às cloroquinas no Estado do Amazonas detectada pelo método in vitro, Acta Amazonica, 7(1):147-148.

HAYES, J. \& Charlwood, D.

1977 - O Anopheles darlingi evita o DDT numa área de malária resistente a drogas. Acta Amazonica, 7(2):289.

- Seazonal changes in Anopheles darlingi populations in a endemic area of ma laria in the Amazon. Acta Amazonica (no prelo).

SMrTH, N.J.H.

1976 - Transamazon highway: A cultural, Ecological analysis of settlement in the lowland Tropics. Berkeley, University of Calif. $372 \mathrm{p}$. Thesis.

Speer, C.A.; ferraroni. J.J. \& Hayes, J.

- Malaria cultivation and immunization (no prelo).

(Aceito para publicação em 20-06-78) 